\title{
Barbara Stambolis, Töchter ohne Väter. Frauen der Kriegsgeneration und ihre lebenslange Sehnsucht
}

Stuttgart Klett-Cotta, 2012, 315 p. , 24,95€

\section{Paul Pasteur}

\section{CpenEdition}

\section{Journals}

Édition électronique

URL : http://journals.openedition.org/ifha/8188

DOI : 10.4000/ifha.8188

ISSN : 2198-8943

Éditeur

IFRA - Institut franco-allemand (sciences historiques et sociales)

Référence électronique

Paul Pasteur, «Barbara Stambolis, Töchter ohne Väter. Frauen der Kriegsgeneration und ihre lebenslange Sehnsucht », Revue de l'IFHA [En ligne], Date de recension, mis en ligne le 14 avril 2015, consulté le 22 septembre 2020. URL : http://journals.openedition.org/ifha/8188; DOI : https://doi.org/10.4000/ifha. 8188

Ce document a été généré automatiquement le 22 septembre 2020.

(CIFHA 


\section{Barbara Stambolis, Töchter ohne Väter. Frauen der Kriegsgeneration und ihre lebenslange Sehnsucht}

Stuttgart Klett-Cotta, 2012, 315 p. , 24,95€

\section{Paul Pasteur}

Inspiré de Söhne ohne Väter (Des fils sans père) de Jürgen Reulecke qui signe une postface, cet ouvrage de Barbara Stambolis «Des filles sans père » se présente comme une enquête auprès de 120 femmes nées pendant la guerre ou l'immédiate-après-guerre et qui ont grandi sans connaître leur père ou sans l'avoir vu revenir de guerre ou de captivité. Ces femmes semblent avoir grandi dans l'ancienne République fédérale. L'auteure se réclame de l'histoire culturelle, mais a tendance à oublier les bases mêmes de toute méthode historique : sérier, quantifier et rappeler le contexte aussi souvent qu'il est nécessaire. L'auteure prend trop souvent les témoignages recueillis à la fin des années 2000 pour argent comptant, oubliant que non seulement les États, les institutions mais aussi les individu-e-s réécrivent leur propre histoire. On apprend qu'« une grande partie» des sondées sont devenues enseignantes, est-ce donc un hasard si elles ont répondu au long questionnaire envoyé par l'auteure ? L'historien-n-e professionnel-le ne peut se contenter de présenter le résultat d'entretiens ou de questionnaires sans revenir sur le contexte historique et sans croiser les sources. D'une manière générale, la culture historique, même de la RFA de Bonn, apparaitt maigre et si l'auteure cite l'ouvrage d'Anna Schnädelbach sur les veuves de guerre (voir la revue $2010 \mathrm{http} / /$ ifha.revues.org/6400 ), elle n'en tire malheureusement pas toutes les conséquences en termes d'interprétation.

Néanmoins, les historiens travaillant sur les années 1950 ou sur les enfants grandissant sans père trouveront quelques précieux renseignements.

Quelques pistes hautement intéressantes sont laissées à l'état de friches, ainsi en est-il de la référence permanente à Hänsel et Gretel, les tirages du livre, le nombre de représentations dans l'ancienne RFA, le nombre de diffusions de l'opéra de Humperdinck auraient été les bienvenus et surtout un risque d'interprétation allant au 
delà de la paraphrase des témoignages des sources. Autre piste intéressante non exploitée : le magazine Pinguin publié par Erich Kästner dans la zone d'occupation britannique. D'autres ne sont même pas envisagées, malgré leur importance, comme la presse des Églises ou de celle des associations.

Tout au long de l'ouvrage, on ne peut s'empêcher de se demander ce que ces femmes ont de spécifique, elles ont été privées de leur père dans leur enfance et adolescence, mais aucune comparaison n'est tentée avec les autres femmes de la même génération ou avec des femmes privées de père pour d'autres raisons que la guerre ou la captivité. Le fait que cette absence de père ait dû être un phénomène de masse et ait donc dû avoir entrainé des stratégies particulières des petites filles ou des adolescentes n'est pas pris en compte. Qu'est-ce qui est différent au niveau de l'interrogation sur l'adhésion éventuelle du père au national-socialisme, mais aussi de la formation, de l'éducation sexuelle, des rencontres prénuptiales, de la réussite de leur mariage, de l'image du prince charmant, de leur engouement pour la musique, entre ces femmes élevées sans père et celles qui en ont eu un présent? Ces questions restent sans réponse.

L'ouvrage se divise en onze chapitres, le onzième propose des extraits des réponses aux questionnaires, les autres abordent "l'ombre des pères ", «le père absent en tant que thème de vie ", «le prix de la survie ", "vie de femme sans hommes ", "grandir sans père ", " projets de vie féminins ", " partenaire et enfants ", « Bilan d'histoire de vie ». Dans un neuvième chapitre, l'auteure s'interroge sur les perspectives, sur les histoires visibles et invisibles; dans un dixième chapitre, elle propose un résumé expliquant comment on prend en compte et on assume de la perte du père.

\section{INDEX}

Index chronologique : Époque contemporaine

Thèmes : Histoire des femmes et du genre

\section{AUTEUR}

\section{PAUL PASTEUR}

Université de Rouen 